\title{
Mineralization in mammalian growth, aging, and disease
}

\author{
Anastasios Johannes Tousimis* and Heide B-Schatten** \\ * Biodynamics Laboratories, 2211 Lewis Avenue, Rockville, MD 20851 \\ ** Dept. of Veterinary Pathobiology, University of Missouri-Columbia, Columbia, MO 65211
}

Alfred Sherwood Romer, in his "Ancient History" of Bone, reminds us that "in the study of human affairs, current problems are of major concern; but a knowledge of the history of man...lends a vision towards their solution... and so is the study of...bony tissues...in modern organisms". In our studies, we examined "normal" growth mineralization, those due to trauma (external physical and chemical), aging, and disease, primarily on humans. In the study of the development of vertebrates and specifically mammals, one cannot escape the phylogenetic sequence in the evolutionary sense, as per suggestions by E.S. Goodrich, ${ }^{2}$ that cyclostomes followed by chondrichthyes and then osteichthyes, we could be part of them.

The obvious observation of this short introduction is that cartilage (chondroid structures) is involved in any, if not all, mineralization. The advent of electron microscopy (both TEM and SEM) as well as secondary ion microscopy and microanalysis has opened a new approach to study bone, its origin, structure, and function.

The mineralization and bone formation of any shape and functional design starts with an active cellular zone at either end of long bones. In our studies, we will mention the mineralization in the epiphyseal plates and specifically that of several mammalians. We report the organization of chondrocytes, a predeterminate structural order, their secretion that forms the extracellular matrix, and finally their maturation and their death associated with the formation of mineral nanoparticles. In Figure 1, the size and shape of these particles is consistent and their elemental composition is the same as that of hydroxyapatite as shown by electron diffraction, and electron probe microanalysis (Figure 2). These deposits are limited in the matrix and not immediately surrounding the cell. Similar nanocrystalites are also seen in mitochondria of the disintegrating chondrocytes of the same tissue (Figure 3). Similar results have been obtained in the elastin portion of the human aorta (Figure 4). In addition to these structures, the "mineral" deposits of the senile human pineal gland were analyzed and shown to consist of similar nanocrystalites with the same chemical composition as well as those observed in the scleral plaques of the aging scleral plaques of the human eye. The only exception to the comparable results is that of the human kidney stones, where calcium oxalate prevails.

In conclusion, mineralization of higher vertebrates shows a unique and remarkable development with current ultrastructural theories presenting a composite of hydroxyapatite nanocrystals embedded in a flexible matrix composed of elastin.

[1] Romer, Alfred Sherwood. The "Ancient History" of Bone. Annals of the New York Academy of Sciences. Vol. 109, 168-176 (1963).

[2] Goodrich, E.S. Vertebrata Craniata, A Treatise on Zoology, Part IX. Adam and Charles Black, London, England (1909). 


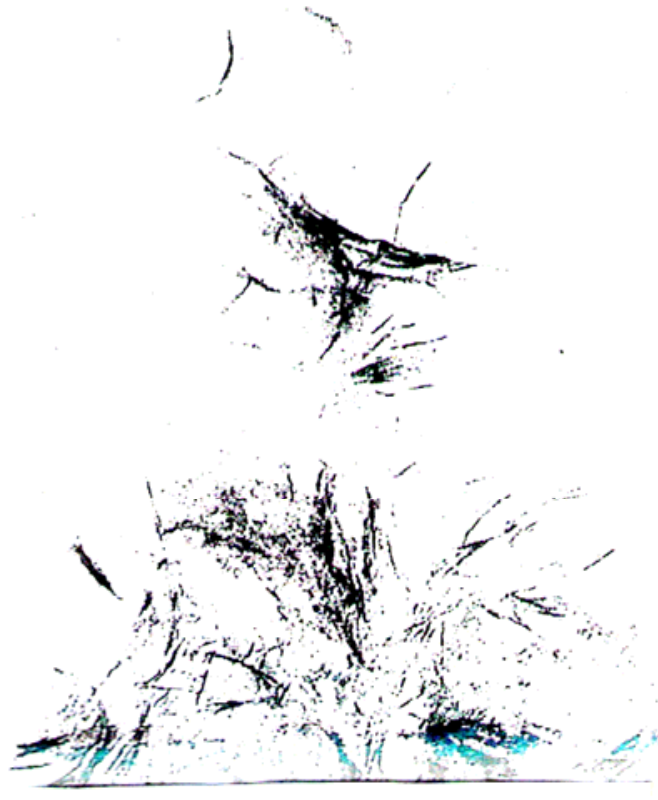

Fig. 1 Typical nanocrystals in the matrix of the epiphyseal plate.

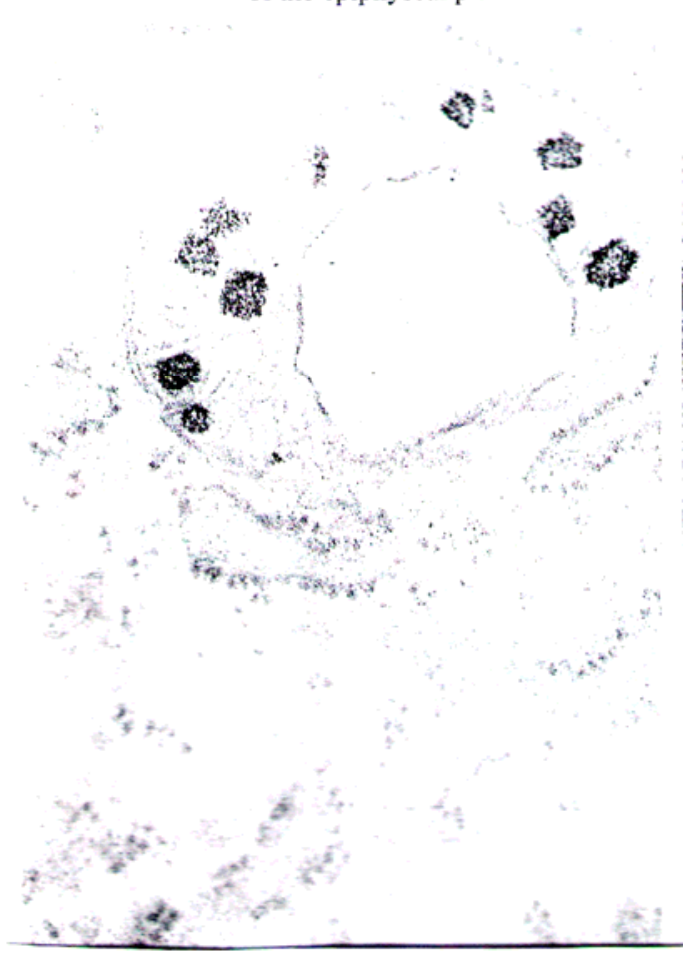

Fig. 3 TEM of a mitochondrion from a Maturation zone chondrocyte shown nanocrystals.

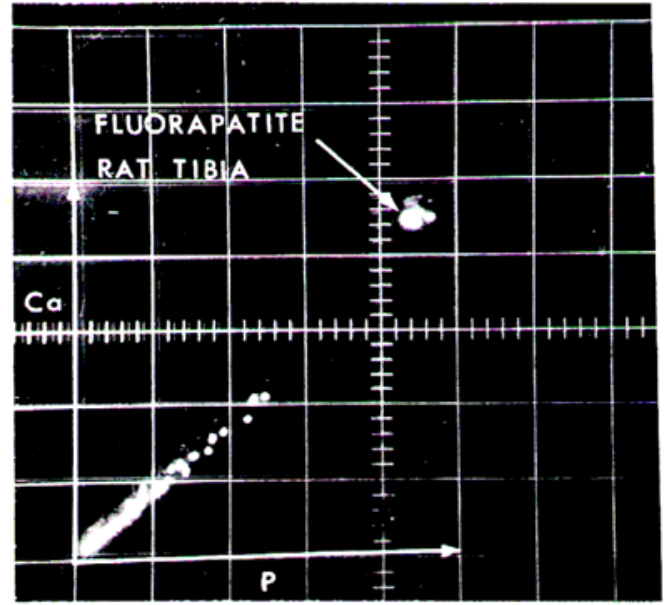

Fig. 2 The calcium/phosphorus ratio as the number of hydroxyapatite crystalites increase in agreement with the mineral standard.

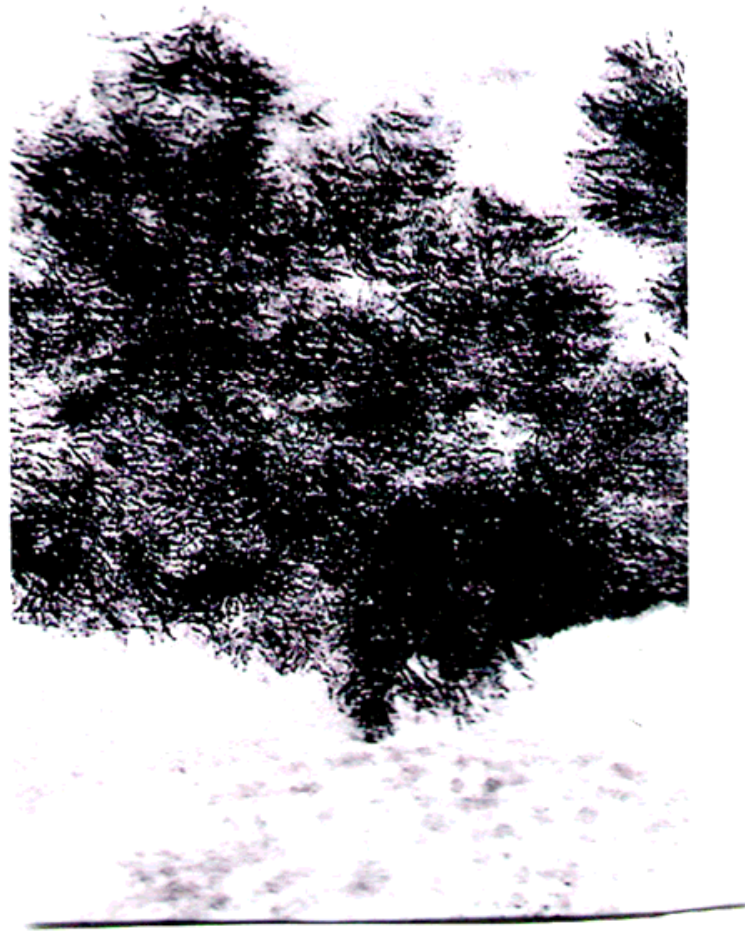

Fig. 4 Hardening (sclerosis) of the human aorta wall. Nanocrystals are seen in the elastin portion, lower part are collagen fibers. TEM. 